\title{
My Hopes for 2015: Letter from the President of Korean Cleft Palate-Craniofacial Association
}

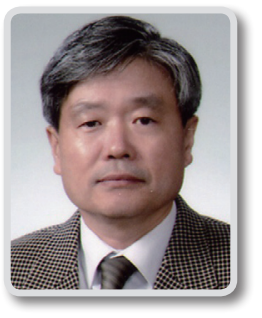

Jeong Yeol Yang

President of Korean Cleft Palate-Craniofacial Association
Dear Members of Korean Cleft Palate-Craniofacial Association,

Our association, Korean Cleft Palate-Craniofacial Association (KCPCA), hosts symposiums in March and September of every year. We also co-host academic conferences in November along with the Korean Society of Plastic \& Reconstructive Surgeons. These academic conferences cover a wide spectrum of topics, which are appropriate for training and senior surgeons alike. We look forward to seeing you at these conferences.

Through the efforts of previous presidents, the association was welcomed as a guest society by the European Association for Cranio-Maxillo-Facial Surgery to the annual conference meeting. In early February this year, 13 association members and the chairman of the board of directors, Dr. Yong Wook Kim, were invited to the annual meeting by the Egyptian Society of Plastic \& Reconstructive Surgeons, which was held in Sharm El-Sheikh. Our members gave several highlight presentation and received positive accolades from our esteemed Egyptian colleagues. As a society, we are well on our way to becoming an internationally recognized society in the craniofacial field.

Not everything has been in smooth sailing for us, however. Last year, we stood in the center of scrutiny from the public for unethical conducts motivated by greed of few members of our profession. It is my hope that the year 2015 will be a year, in which we will begin to uphold the principles of our profession and restore the confidence from our medical colleagues, the public, and most importantly, our patients.

On behalf of the administrative board, I extend a welcome challenge to the association members to join us, in working towards a more scholarly and upright future, both here at home in Korea and internationally.

We thank you for the continued confidence and support in the association.
Correspondence: Jeong Yeol Yang

Department of Plastic and Reconstructive Surgery, Chosun University College of Medicine, 365 Pilmun-daero, Dong-gu, Gwangju 501-171, Korea

E-mail: jyyang@chosun.ac.kr

Received February 28, 2015 / Revised February 28, 2015 / Accepted March 3, 2015 